\title{
TELEVISION FOR SCHOOL SCIENCE
}

$\mathrm{T}$ HE economic strength of Western Europe depends increasingly on the application of science and technology and, consequently, on a growing supply of scientific and technical manpower. Unfortunately, there is a growing shortage of teachers and schools are already overburdened. School television could perhaps be of considerable assistance in overcoming such deficiencies in educational facilities. The medium has proved effective in various countries, including France, Italy, the United Kingdom and the United States of America, while its scope has been considerably extended by recent technical developments such as the use of closed-circuit systems. A year ago, the Organization for European Economic Co-operation, believing that much could be gained from the experience of countries which had been exploiting the new medium for teaching science subjects, conducted a survey on the present status of school television in Western Europe, and convened a forum of international experts in this field, "Teaching through Television", during June 1960. The report of this meeting is now available*.

The seminar was held at Ashridge (Nr. Berkhamsted), with three main objectives: to give countries beginning educational television an opportunity to learn from the experience of those where educational television has been in operation for some years; to encourage the development of international contacts, on a personal basis, between programme producers and to seek ways and means to secure improved co-ordination in securing sources of informa-

- Organization for European Economic Co-operation: Office for Scientiffc and Technical Personnel. Television for School Science: Report on an O.E.E.C. Seminar, Ashridge (England), July 1960. Pp.v+181, (Paris: Organization for European Economic Co-operation, 1961.) tion on programme material. Two different tendencies emerged during the conference: the use of school television as a complete substitute for traditional teaching (this is the case with the 'Telescuola' in Italy, where there is a severe shortage of teachers and schools) or as a complementary broadcast for use in the framework of normal school activities. School television is also used for teachers' training, as, for example, in the 'continental classroom' of the United States.

Other topics included technical aspects of programme-production problems, the use of films, of consultants, advisers and specialists, of economical visual techniques and devices. Future developments were concerned chiefly with the use of closed-circuit television. Great progress has been made in the development of inexpensive systems which can be used to link any number of classrooms (or even schools) to a central sehool studio from which live or recorded lessons are 'piped' to pupil audiences. During the seminar it became clear that great possibilities exist for the exchange of information on films and other material and the international exchange of production facilities and personnel.

The report also provides information about the Tele-Lille mathematics experimental project, lists of films available for educational television, examples of science programmes, and a list of scientific film associations and their addresses. A small group has been set up to carry out the recommendations (improved information, training school science producers, research, experimental projects, co-operation with industries) of the seminar. It will report progress to the Organization for European Economic Co-operation and ensure liaison with organizations concerned with science teaching, films and television.

\section{THE INSTITUTE FOR THE ENCOURAGEMENT OF SCIENTIFIC RESEARCH IN INDUSTRY AND AGRICULTURE, BRUSSELS}

$T$ HE annual report of the Institute for the Encouragement of Scientific Research in Industry and Agriculture, Brussels, for $1960^{*}$ records sixty subsidies, totalling 264,772,837 francs, during the year, including 3 million francs to the Committee for the Study and Exploitation of Electronic Computers, and estimates that 267 research workers and 529 technicians are thereby employed. The National Centre for Metallurgical Research received 29,275,000 franes for analytical research, investigations on the physical metallurgy of steel, analytical research on the physical metallurgy of zinc, research on the agglomeration of minerals, etc., while the Belgian Society for Nitrogen and Chemical Products, of Marly, received 25,898,000 for research on the pyro. lysis of hydrocarbons, on the synthesis of vinyl chloride and other investigations in the field of heterogeneous catalysis.

The Committee for Mapping the Soils and Vegetation of Belgium received a grant of 20,155,000 francs

* Institut pour l'Encouragement de la Recherche Scientiflque dans $l^{\prime}$ Industrie et 1'Agriculture. Rapport Annuel Exercice, 1960. Pp. 255. (Bruxelles: Institut pour l'Encouragement de la Recherche Scientifique dans l'Industrie et $1^{\prime}$ Agriculture, 1961.) for its systematic study of the pedological character of the soils and towards the pedological map of Belgium, while grants of $10,000,000$ francs and $8,560,000$ francs went to the Centre for the Study of High Polymers for its work on high polymers and their degradation, on photopolymerization initiated by silver salts and the stability of the polymers and for some industrial work on the extrusion of erystallizable polymers. The Centre of Applied Electronics received 12,450,000 francs for work on passive circuits, on amplifiers, modulators and oscillators of transistors and on industrial circuits; $11,505,000$ francs went to the Committee for the Study of Diseases and Feeding of Farm Animals; 9,950,000 francs to the Centre for Scientific and Technical Research of the Metal Manufacturing Industry for investigations on the adaptation of numerical techniques to other machine tools and in automation, as well as $2,980,000$ franes for research on resistance to fatigue of cooled alloys, etc.; 8,317,590 francs to the National Centre of Metallurgical Research for low-temperature furnace research, and 7,474,273 francs to the Scientific and Technical Centre of the Belgian Textile Industry for research on wool, cotton, 
jute, linen and rayon, as well as 1,534,000 franes for investigations of the utilization of acrylic fibres.

A grant of 7,050,000 francs went to the Committee for the Study of the Solid State for continuation of work on the mechanism of photographic processes and of sensitization; $6,520,000$ francs to the National Committee for the Study of Fruit Cultivation; $5,360,000$ francs to the Committee for the Scientific and Technical Study of Milk and its Derivatives; $4,300,000$ francs to the National Centre for Research on Herbage and Forage for botanical, phytosociological and ecological studies on herbage and on the control of adventitious plants of the prairies; $4,050,000$ francs to the Centre for Scientific and Technical Research on the Conservation of Vegetables; and 3,817,000 francs to the Belgian Centre for the Study and Documentation of Water, for studies on water supply, corrosion, residual water, and on atmospheric corrosion.

The Belgian Institute of High Polymers received a grant of $3,710,000$ franes towards its experimental thermodynamic work at high pressures on the inhibition of the explosiveness of acetylene; the Centre for Studies and Research in Agriculture, $3,590,000$ francs for research on cultivation in mineral substrates and on the mineral requirements of vegetables; the Scientific and Technical Centre of the Brewing, Malt and Related Industries, 3,316,000 francs; and the Committee for the Study of the Structure of the Soil, 3,000,000 francs. Among other grants may be mentioned 2,770,000 francs for studies on diseases of cereals; $2,280,000$ francs for ceramic research; $2,125,000$ frencs for research on the synthesis of saturated heterocyclic amines substituted in position 3 or $4 ; 2,065,000$ franes for phytovirological research; 2,049,500 francs for research on paints, varnishes and printing inks; $2,040,000$ francs for studies on the creep of metals at high temperatures; 2,000,000 francs for work on new penicillins and the new antibiotic, staphylomycin; and 1,840,000 francs for research on the culture of medicinal plants.

\section{HELICOPTER STATIONS IN LONDON}

$\mathrm{I}^{\mathrm{N}}$ July 1959, the Minister of Transport and Civil Aviation formed a committee to consider the setting up of helicopter stations in the London area, assuming: (1) that the helicopter is developed to the point of offering sufficiently low fares on regular services to attract large numbers of passengers for inter-city flights on international routes and possibly internal ones as well; (2) that the helicopter will not offer fares sufficiently low for mass travel, but will meet the needs of small numbers of travellers for whom the extra time saved is more important than the money spent.

In its recommendations *, the Committee assumes that regular services between London and the near Continental cities with helicopters carrying twentyfive passengers or more will begin in 1965 , or soon after, that fares will be offered approximating those of first-class 'fixed-wing' services, and that services to provincial cities in the United Kingdom will follow if fares can be reduced to compete with those of the other forms of transport.

Allowing for executive and charter flights with passengers, freight and mail as well as regular services, the total traffic could amount to 20-25 helicopter movements in a peak hour, with a mixture of single- and multi-engined types by 1975 , when the heliport would have to handle $1 \frac{1}{2}$ million passengers a year. These estimates, the committee suggests, represent a reasonable basis for planning the area required for the first permanent heliport.

In order to provide enough space for helicopters to land and take-off and for working stands (for loading, unloading, minor maintenance, etc.) at the heliport, a level area of about 8 acres would be required to handle 25 movements an hour. In addition, an area of about 4 acres would be needed for terminal buildings and car parks, which, if the landing area were on a raised platform, could be provided on a lower deck or at ground-level.

For reasons of air traffic control, the capacity of a heliport could not be increased much beyond 25 movements an hour even by providing an additional

- Ministry of Aviation. Report of the Committee on the Planning of Helicopter Stations in the London Area. Pp. 105 (10 plans). (London: H.M.S.O., 1961.) 7s. net. landing area, which would involve a disproportionate amount of extra space.

The heliport should satisfy the following requirements :

(1) Since the appeal of the helicopter depends on saving time, the heliport should be brought as close as possible to the main source and destination of a substantial proportion of the traffic. More specifically, it should not be much more than a quarter of an hour from Grosvenor Square, and ideally, between the West End and the City. Because of the helicopter's potentialities for freight and mail, nearness to one of the sorting offices of the General Post Office would also be an advantage.

(2) It should be conveniently placed for all forms of surface transport, good road connexions and local traffic access being especially important in view of the high proportion of passengers who will travel to the heliport in private cars and taxicabs.

(3) It should have sufficient unobstructed approaches to enable operations to continue safely in all weathers, allowing for a climb and descent gradient not much steoper than 1 in 4 . This may entail some restrietion on building heights in the neighbourhood of the site.

(4) To be usable at all by single-engined helicopters it should be beside the River Thames.

(5) In order to avoid conflict between helicopter and fixed-wing traffic to and from London Airport, it should not be located farther west than Battersea. For effective control of air traffic, it is unlikely that two sites on the Thames within easy reach of the West End could be simultaneously used to capacity.

(6) It should be compatible with the proposals of the County of London development plen.

(7) It should be so placed as to avoid interference with the normal life and work of the neighbourhood.

Measurements of the noise of the various types of helicopters indicate that noise in level flight at 1,000 ft. would be no greater than traffic noises in a busy street, but, since it will be more widespread, routes should be chosen which, so far as possible, reduce flights over areas particularly sensitive to noise. The greatest noise will be in the immediate locality of the 